Original Research Article

\title{
A study on medication adherence, medication related challenges faced and coping strategies adopted by visually impaired subjects in a tertiary care hospital
}

\author{
Apoorva R. ${ }^{1 *}$, K. Vasundara ${ }^{2}$, Umadevi R. S. ${ }^{3}$
}

${ }^{1}$ Department of Pharmacology, SIMSAR, KGF, Karnataka, India

${ }^{2}$ Department of Pharmacology, ${ }^{3}$ Department of Ophthalmolgy, KIMS, Bangalore, Karnataka, India

Received: 18 August 2017 Accepted: 27 August 2017

\section{*Correspondence to:}

Dr. Apoorva R.,

Email: anuka.7root@gmail.com

Copyright: (C) the author(s), publisher and licensee Medip Academy. This is an openaccess article distributed under the terms of the Creative Commons Attribution NonCommercial License, which permits unrestricted noncommercial use, distribution, and reproduction in any medium, provided the original work is properly cited.

\begin{abstract}
Background: Visual impairment poses a significant threat to proper medication practice leading to medication related challenges and some adopted self coping strategies with substantial impact on medication adherence. Visually impaired are potentially more likely to have unsafe medicine related practice which by itself is more rampant in general population. Studies related to them are largely unexplored and can provide data to improve disease management and health related quality of life. Objectives was to study the level of medication adherence, medication related challenges and self adopted coping strategies in visually impaired people.

Methods: A cross sectional descriptive study enrolling 204 subjects with VI was done. Medication adherence was assessed using MMAS. Medication related challenges and self-adopted coping strategies was assessed by using pre-validated semi-structured questionnaire.

Results: Majority of the subjects showed medium medication adherence with forgetfulness to take medicine as the main reason for non adherence. Difficulty in remembering the instructions, spilling of liquid medicine, taking wrong dose, difficulty in using topical medications were the most common challenges faced by them in daily drug administration. To overcome challenges locating the drugs at different places, finger felt volume for liquid medication, textural feeling of the drug or container, time tracking were the major self adopted coping strategies by the visually impaired subjects.

Conclusions: Creating awareness of the medication related problem faced by visually impaired helps to provide adequate assistance to medication use and improve proper health care services in them.
\end{abstract}

Keywords: Medication related challenges, Self adopted coping strategies, Visual impairment

\section{INTRODUCTION}

Visual impairment is a major global public health problem. According to WHO 2014, estimated number of visually impaired worldwide are 285 million, which includes people with blindness and low vision, and India accounts for $20 \%$ of global blind population. ${ }^{1}$

Visual impairment is a major issue imposing significant burden to both individual and society. ${ }^{2}$ It is a detrimental physical condition with deep emotional, psychological, social and economic implications. It adversely affects their daily basic activities, causing difficulties in cognition to surround and people, health related quality of life and psychosocial life leading to frequent injuries, anxiety and depression. Medication nonadherence is more prevalent in visually impaired elderly individuals and show increased anxiety related to medication management and causes dependency on others to obtain necessary drug information and assistance. ${ }^{3}$ The presence of various 
specific health challenges in visually impaired along with other age related diseases makes them frequent consumers of medicine, potentially exposing them for unsafe medical practices, as non-adherence to medicines which by itself is common in general public with normal vision. ${ }^{4}$ Visual impairment leads to poor medication adherence to the therapy and lack of cost effectiveness in medicine use. ${ }^{5-7}$

Assessing on medication adherence, the difficulties faced by visually disabled people while using medicines and their self-adopted coping strategies helps people with visual impairment to build gap in their knowledge, skill and attitude and thus make them more compliant towards safe and effective medicinal use. With limited studies, especially in Indian visually impaired population, the present study on medication adherence in visually impaired people, their medication related challenges and self-adopted coping strategies in ophthalmology department in a tertiary care hospital is taken up.

\section{METHODS}

This cross sectional descriptive study was done to determine the level of medication adherence and identify the medication-related challenges and self adopted coping strategies among visually impaired subjects in a tertiary care teaching hospital. Study subjects included various inpatients and outpatients of Ophthalmology Department, KIMS Hospital and Research Center, Bangalore and various centers of National Federation of Blind in Bangalore. This study was carried out from January 01, 2015 to June 30, 2016. Purposive sampling involving 204 visually impaired inpatients and outpatients of ophthalmology department, KIMS Hospital and Research Centre, Bangalore and various centers of National Federation of Blind in Bangalore.

\section{Inclusion criteria}

- Visually impaired subjects from either gender aged 18years and above receiving medication for any acute or chronic illness.

- Visual acuity in best corrected eye ranging from $<6 / 18$ to $<3 / 60 \mathrm{with} /$ without perception of light.

- Willingness to give informed consent in the presence of legally authorized representative as witness.

\section{Exclusion criteria}

- Subjects with corrected visual acuity of $6 / 6$ to $6 / 18$ in the better eye.

- Subjects visually able to identify the medication characteristics.

- Subjects with impairment of speech and/or hearing.

\section{Study procedure}

Following Institutional Ethics Committee approval and clearance, 204 consecutive cases were recruited for the present study. Written informed consent was obtained from all the study subjects in the presence of legally authorized representatives as witness after fully explaining the study procedure to their satisfaction. The study subjects will be interviewed by using pretested semi structured questionnaire as a tool. After obtaining demographic data, history of any illness, both current and past will be recorded. Medication adherence will be assessed by using Morisky Medication Adherence Scale (MMAS). ${ }^{8}$ Medication related challenges and self-adopted coping strategies will be assessed by using pre-validated semi structured questionnaire.

\section{Statistical analysis}

The data collected was analysed by using descriptive statistics, namely mean and standard deviation. The results were depicted in the form of Tables. Statistical software namely SPSS v20 was used for analysis of data and Microsoft Word to generate Tables.

\section{RESULTS}

Table 1 shows the frequency of age distribution of the study subjects. The percentage of the subjects in the age group between $18-30$ years were $35.8 \%, 2.9 \%$ were in the age group of $31-40$ years, $4.4 \%$ were in the age group of 41-50 years, $15.7 \%$ were in the age group of 51-60 years, $28.9 \%$ were in the age group of $61-70$ and $12.3 \%$ were in the age group of above 70years. Among the study subjects the eldest was $81 \mathrm{yrs}$ old and youngest was aged $18 \mathrm{yrs}$. The mean age was 49.41 years.

Table 1: Age distribution of study subjects $(n=204)$.

\begin{tabular}{|lll|}
\hline Age (yrs) & Number of subjects & Percentage (\%) \\
\hline $18-30$ & 73 & 35.8 \\
\hline $31-40$ & 6 & 2.9 \\
\hline $41-50$ & 9 & 4.4 \\
\hline $51-60$ & 32 & 15.7 \\
\hline $61-70$ & 59 & 28.9 \\
\hline$>70$ & 25 & 12.3 \\
\hline Total & 204 & 100.0 \\
\hline
\end{tabular}

Equal number of male (50\%) and female (50\%) visually impaired subjects were present in our study.

Table 2: Gender distribution.

\begin{tabular}{|lll|}
\hline Gender & Number of subjects & Percentage $(\%)$ \\
\hline Male & 102 & 50.0 \\
\hline Female & 102 & 50.0 \\
\hline Total & 204 & 100.0 \\
\hline
\end{tabular}

Table 3 shows the type of visual impairment in subjects. Low vision in both eye was seen in 100 subjects, ninetysix subjects had total blindness in both eye, four had right eye blindness with low vision in left eye and equal number of subjects (4) had left eye blindness with low vision in right eye. 
Table 3: Visual impairment.

\begin{tabular}{|lll|}
\hline $\begin{array}{l}\text { Type of visual } \\
\text { impairment }\end{array}$ & $\begin{array}{l}\text { Number } \\
\text { of subjects }\end{array}$ & $\begin{array}{l}\text { Percentage } \\
(\%)\end{array}$ \\
\hline $\begin{array}{l}\text { Total blindness in both } \\
\text { eye }\end{array}$ & 96 & 47.06 \\
\hline $\begin{array}{l}\text { Right eye blind with low } \\
\text { vision in left eye }\end{array}$ & 4 & 1.96 \\
\hline $\begin{array}{l}\text { Left eye blind with low } \\
\text { vision in right eye }\end{array}$ & 4 & 1.96 \\
\hline Low vision in both eye & 100 & 49.02 \\
\hline Total & 204 & 100.0 \\
\hline
\end{tabular}

Majority $(85.3 \%)$ of the subjects were taken care by caregivers and $14.7 \%$ had no caregivers as shown in Table 4.

Table 4: Caregivers $(n=204)$.

\begin{tabular}{|lll|}
\hline Caregiver & Number of subjects & Percentage (\%) \\
\hline No & 30 & 14.7 \\
\hline Yes & 174 & 85.3 \\
\hline Total & 204 & 100.0 \\
\hline
\end{tabular}

Most (86.3\%) of the caregivers in our study had normal vision, and in $13.7 \%$ of subjects the caregivers were by themselves visually impaired as shown in Table 5.

Table 5: Visually impaired caregivers $(n=174)$.

\begin{tabular}{|lll|}
\hline $\begin{array}{l}\text { Visually impaired } \\
\text { caregivers }\end{array}$ & $\begin{array}{l}\text { Number of } \\
\text { subjects }\end{array}$ & Percentage (\%) \\
\hline No & 146 & 83.90 \\
\hline Yes & 28 & 16.10 \\
\hline Total & 174 & 100.00 \\
\hline
\end{tabular}

Table 6 summarizes the medication adherence among visually impaired according to MMAS. Majority of them (71.6\%) showed medium medication adherence followed by $27.9 \%$ showed low medication adherence and $0.5 \%$ of them showed high medication adherence towards prescribed medication. There was no statistically significant difference between male and female subjects in medication adherence.

Table 6: Medication adherence $(n=204)$.

\begin{tabular}{|lll|l|}
\hline $\begin{array}{l}\text { Morisky } \\
\text { Medication } \\
\text { Adherence Scale } \\
\text { (MMAS) }\end{array}$ & $\begin{array}{l}\text { Male } \\
\mathbf{n}(\%)\end{array}$ & $\begin{array}{l}\text { Female } \\
\mathbf{n}(\%)\end{array}$ & $\begin{array}{l}\text { Total } \\
\mathbf{n}(\%)\end{array}$ \\
\hline Low adherence & $29(14.2)$ & $28(13.7)$ & $57(27.9)$ \\
\hline $\begin{array}{l}\text { Medium } \\
\text { adherence }\end{array}$ & $72(35.3)$ & $74(36.3)$ & $\begin{array}{l}146 \\
(71.6)\end{array}$ \\
\hline High adherence & $1(0.5)$ & 0 & $1(0.5)$ \\
\hline Total* & $\begin{array}{l}102 \\
(50.0)\end{array}$ & $\begin{array}{l}102 \\
(50.0)\end{array}$ & $\begin{array}{l}204 \\
(100.0)\end{array}$ \\
\hline
\end{tabular}

*p $>0.05$, not statistically significant
Self administration of medication was seen in 126 subjects and 78 of them were not able to self administer the medication by themselves. Self administration of medication was equally seen $(p>0.05$, NS) in both male and female subjects. Majority (126) self administered drugs by themselves inspite of presence of caregivers.

Table 7: Self administration of medication $(n=204)$.

\begin{tabular}{|llll|}
\hline $\begin{array}{l}\text { Self administration } \\
\text { of medication }\end{array}$ & Male & Female & Total (n) \\
\hline Yes & 61 & 65 & 126 \\
\hline No & 41 & 37 & 78 \\
\hline Total* & 102 & 102 & 204 \\
\hline
\end{tabular}

*p $>0.05$, not statistically significant

Table 8: Medication related challenges $(n=126)$.

\begin{tabular}{|lll|}
\hline Challenges faced* & $\begin{array}{l}\text { Number of } \\
\text { subjects }\end{array}$ & $\begin{array}{l}\text { Percentage } \\
(\%)\end{array}$ \\
\hline $\begin{array}{l}\text { I couldn't locate where } \\
\text { the drugs were kept }\end{array}$ & 42 & 33.33 \\
\hline $\begin{array}{l}\text { I couldn't identify the } \\
\text { separate drug containers }\end{array}$ & 81 & 64.29 \\
\hline $\begin{array}{l}\text { I have taken the wrong } \\
\text { medicine }\end{array}$ & 56 & 44.44 \\
\hline $\begin{array}{l}\text { I didn't know the correct } \\
\text { dose }\end{array}$ & 122 & 96.80 \\
\hline $\begin{array}{l}\text { I had taken the wrong } \\
\text { dose }\end{array}$ & 126 & 100.00 \\
\hline $\begin{array}{l}\text { I couldn't see the clock } \\
\text { to decide on the time }\end{array}$ & 87 & 69.05 \\
\hline I missed a dose/doses & 124 & 98.40 \\
\hline I spilled my medicine & 126 & 100.00 \\
\hline $\begin{array}{l}\text { I couldn't complete the } \\
\text { full course of treatment }\end{array}$ & 72 & 57.14 \\
\hline $\begin{array}{l}\text { I found it difficult to use } \\
\text { liquid medicines }\end{array}$ & 64 & 50.79 \\
\hline $\begin{array}{l}\text { I found it difficult to use } \\
\text { topical formulations }\end{array}$ & 122 & 96.83 \\
\hline $\begin{array}{l}\text { I found it difficult to } \\
\text { remember the } \\
\text { instructions }\end{array}$ & 126 & 100.00 \\
$*$ Overlapping of challenges faced & & \\
\hline
\end{tabular}

Table 8 summarizes the various challenges faced by the visually impaired subjects in consuming medications. There was overlapping of challenges faced by them. Majority of them $(100 \%)$ had taken wrong dose, spilled liquid medication while consuming, and found it difficult to remember the instructions given by the prescriber. $98.4 \%$ of them missed the regular doses, $96.83 \%$ found difficulty in using topical medications like applying eye drops, ear drops, nasal spray and inhalers and the same percentage also did not know the correct dose, $69.05 \%$ of them could not keep track of time to take drug. $64.29 \%$ of them had difficulty in identifying the separate drug containers, $57.14 \%$ were not able to complete the full course of treatment, $50.79 \%$ found difficulty in measuring 
and taking liquid medications, $44.44 \%$ of them had taken wrong medicine and $33.33 \%$ could not locate where the drugs were kept.

Table 9 shows majority (116) of subjects adopted methods to overcome challenges in daily drug administration. 10 of them did not adopt any methods as they were totally dependent on their caretakers. More female subjects than males adopted methods to overcome challenges in drug administration which was statistically significant.

Table 9: Methods adopted to overcome challenges $(n=126)$.

\begin{tabular}{|llll|}
\hline Methods adopted & Male & Female & Total (n) \\
\hline Yes* & 54 & 62 & 116 \\
\hline No & 8 & 2 & 10 \\
\hline Total & 62 & 64 & 126 \\
\hline
\end{tabular}

$* \mathrm{p}<0.05$, statistically significant

There was overlapping of methods adopted by the subject to overcome the challenges. Majority of them (100\%) adopted method to easily locate the drugs by keeping them at different places, and taking liquid medication by using finger felt volume followed by $99.1 \%$ could identify drugs by feeling its texture, size and shape and $97.4 \%$ could locate the drugs by differentiating drug containers in its size, shape and texture. Majority of them $(n=100)$ used speaking watch which aided them to remind drug intake by keeping track of time as shown in Table 10.

\section{Table 10: Types of methods adopted to overcome the} challenges $(n=116)$.

\begin{tabular}{|lll|}
\hline $\begin{array}{l}\text { Types of methods } \\
\text { adopted* }\end{array}$ & $\begin{array}{l}\text { Number } \\
\text { of subjects }\end{array}$ & $\begin{array}{l}\text { Percentage } \\
(\%)\end{array}$ \\
\hline $\begin{array}{l}\text { Locate the drugs by } \\
\text { keeping them at different } \\
\text { places }\end{array}$ & 116 & 100 \\
\hline $\begin{array}{l}\text { Differentiating drug } \\
\text { containers }\end{array}$ & 113 & 97.4 \\
\hline $\begin{array}{l}\text { Feeling its texture, size and } \\
\text { shape }\end{array}$ & 115 & 99.1 \\
\hline $\begin{array}{lll}\text { Using speaking watch } \\
\text { Taking liquid medicine by } \\
\text { using finger felt volume }\end{array}$ & 100 & 86.20 \\
\hline *Overlapping of methods adopted to overcome challenges \\
\hline
\end{tabular}

\section{DISCUSSION}

In the present cross sectional observation study, the visually impaired subjects level of medication adherence, medication related challenges and their self adopted coping strategies were assessed in 204 visually impaired subjects at KIMS Hospital and Research Centre, Bangalore.

Table 1 shows the frequency of age distribution of the study subjects. Majority of the subjects $(35.8 \%)$ in our study were in the age group of 18-30 years reflecting the age of visually impaired people visiting our tertiary care hospital. Mean age of the subjects was 49.41years.

Table 2 shows that there was no significant difference in gender distribution of the study subjects. Table 3 shows the type of visual impairment in study subjects. Low vision (100) and total blindness (96) in both eyes were more common.

Majority (174) of subjects had caregivers (Table 4) in our study. Majority of caregivers (146) had normal vision (Table 5) in our study.

Table 6 summarizes the medication adherence among visually impaired according to MMAS. Majority of them $(71.6 \%)$ showed medium medication adherence. Major reason for non-adherence was forgetfulness to take medicine $(98.4 \%), 57.1 \%$ stopped medication on their own as they felt better, $25 \%$ showed careless attitude towards medication taking behaviour, $10 \%$ stopped medication as they felt medication worsened their disease. There was overlapping of causes for non-adherence to medication.

Daily medication related challenges were faced by total of 126 subjects as they had to self administer the medications on their own inspite of the presence of caregivers, in 174 of total 204 subjects in our study (Table 7).

Table 8 summarizes the various challenges faced by the visually impaired subjects in consuming medications. There was overlapping of challenges faced by them. The findings of challenges faced by the visually impaired in our study like difficulty in drug locating, identifying drug containers, wrong dose administration, time tracking and difficulty in using liquid medication are similar to a previous study. ${ }^{9}$ No fatalities due to improper drug administration were reported by any subjects. The difficulties in consuming medication can lead to under dosing, overdosing, and missing of dose of drugs and also non completion of treatment course adversely affecting the disease process.

According to Table 9, 116 subjects adopted several methods to overcome difficulties and challenges faced during drug administration. More female subjects than males adopted methods to overcome challenges in drug administration which was statistically significant.

Table 10 summarizes the methods adopted by visually impaired subjects to overcome the challenges in selfadministration of the drug. There was overlapping of methods adopted by the subject to overcome the challenges. Majority of them (100\%) adopted method to easily locate the drugs by keeping them at different places, and taking liquid medication by using finger felt volume and could locate the drugs by differentiating drug containers in its size, shape and texture which was similar to a previous study. ${ }^{9}$ Majority of them $(n=100)$ used speaking watch which aided them to remind drug intake by 
keeping track of time. Memorization was one of the methods used by them which was similar to Thailand study. ${ }^{10}$

\section{Limitations}

The limitations of the study are small sample size of the study subjects enrolled. Other limitations are being a cross sectional observational study, the information obtained is based on memory recall. Various other prime confounding variables like socioeconomic, educational and occupational factors that would have affected the study, could have been considered in detail. The programme to create medication awareness and motivation for proper medication behaviour in visually impaired subjects followed by follow up would have benefited the study subjects.

\section{CONCLUSION}

Majority of the subjects showed medium medication adherence which was mainly due to forgetfulness. Most of them faced challenges in daily drug administration inspite of caregivers and self adopted various coping strategies mainly by locating the drugs at different places, using textural feeling and speaking watch.

Funding: No funding sources Conflict of interest: None declared

Ethical approval: The study was approved by the Institutional Ethics Committee

\section{REFERENCES}

1. World Health Organization. Visual Impairment and Blindness. Fact Sheet N0282. Geneva, WHO, Updated August 2014. Available at: http:www.who.int/mediacentre/factsheets/fs282/en/ (last accessed 17 October 2014).

2. McCann RM, Jackson AJ, Stevenson M, Dempster M, McEnlay JC, Cupples ME. Help needed in medication self-management for people with visual impairment: case- control study. Br J Gen Prac. 2012;62:530-7.
3. Smith M, Bailey T. Identifying solutions to medication adherence in the visually impaired elderly. Consult Pharm. 2014;29:131-4.

4. Court H, McLean G, Guthrie B, Mercer SW, Smith DJ. Visual impairment is associated with physical and mental comorbidities in older adults: a cross-sectional study. BMC Medicine. 2014;12:181-8.

5. Crews JE, Campbell VA. Vision impairment and hearing loss among community-dwelling older Americans: implications for health and functioning. Am J Public Health. 2004;94(5):823-9.

6. Nikolaus T, Kruse W, Bach M, Specht-Leible N, Oster P, Schlierf G. Elderly patients' problems with medication. European journal of clinical pharmacology. 1996 Jan 1;49(4):255-9.

7. Gibson M, Knapp P, Raynor T, Pam Turpin, Atkin K, Bradbury $\mathrm{H}$, et al. Medicines information needs of older people with sight loss. 2006. Available at: http://www.rnib.org.uk/aboutus/research/reports/2009 andearlier/minops.doc (last accessed 3 July 2012).

8. Morisky DE, Ang A, Krousel-Wood M, Ward JH. Predictive Validity of a Medication Adherence Measure in an Outpatient Setting. The Journal of Clinical Hypertension. 2008;10(5):348-54.

9. Weeraratne CL, Opatha ST, Rosa CT. Challenges faced by visually disabled people in use of medicines, self-adopted coping strategies and medicine-related mishaps. WHO South-East Asia Journal of Public Health. 2012;1(3):256-67.

10. Riewpaiboon A. How the blind cope with problems of medicine utilization: a study in Bangkok, Thailand. Pharmacoepidemology and drug safety. 2009;18:70812.

Cite this article as: Apoorva R, Vasundara $\mathrm{K}$, Umadevi RS. A study on medication adherence, medication related challenges faced and coping strategies adopted by visually impaired subjects in a tertiary care hospital. Int J Basic Clin Pharmacol 2017;6:2323-7. 